\title{
World enough and form: Why cosmology needs hylomorphism
}

\author{
Author: John G. Brungardt
}

Affiliation: Pontificia Universidad Católica de Chile, Instituto de Filosofía

\author{
Address: \\ Pontificia Universidad Católica de Chile \\ Instituto de Filosofía \\ Av. Vicuña Mackenna 4860 \\ Santiago 7820436 \\ Región Metropolitana \\ Chile
}

\section{Contact:}

jobrungardt@uc.cl

ORCID: 0000-0003-4989-145X

\begin{abstract}
This essay proposes a comprehensive blueprint for the hylomorphic foundations of cosmology. The key philosophical explananda in cosmology are those dealing with global processes and structures, the regularity of global regularities, and the existence of the global as such. The possibility of elucidating these using alternatives to hylomorphism is outlined and difficulties with these alternatives are raised. Hylomorphism, by contrast, provides a sound philosophical ground for cosmology insofar as it leads to notions of cosmic essence, the unity of complex essences, and globally emergent properties. These are used as the basis to account for the aforementioned cosmological explananda and to resolve two problems in the philosophy of cosmology: the meta-law dilemma and the uniqueness of the universe. In summary, cosmology needs hylomorphism because it is able to ground cosmology's efforts as a scientific inquiry. It can do so because hylomorphism philosophically accounts for changing substances and aggregates of substances, the various scales of law-governed behavior measured by the natures of those substances, and how those substances as parts relate to the universe as a whole.
\end{abstract}

Keywords: hylomorphism, philosophy of cosmology, universe, laws, meta-law dilemma 


\section{World enough and form: Why cosmology needs hylomorphism}

Attending to its recent developments, and taking a long view of the history of the discipline during the twentieth century, it is no longer wise to ask whether modern cosmology has need of philosophy and answer in the negative. ${ }^{1}$ Cosmology needs philosophy. More controversially, however, cosmology needs a particular philosophy, the one that defends hylomorphism. Hylomorphism is a general account of changing and changeable beings that appeals to a complementary pair of explanatory principles of change: a determining form (morphe) and determinable matter (hyle). In what follows, we offer a systematic blueprint for the hylomorphic foundation of cosmology. This hylomorphic foundation grounds the possibility of global regularities and structures, the regularity of global regularities, and the existence of the global as such. We obtain these results by arguing that the universe is a whole whose members are substances; that the universe at the global scale exhibits law-governed behaviors; and that the universe is not merely an aggregate of substances but a system, a unity of order.

The original proponent of hylomorphism noted that in order to articulate a philosophical topic well, the matter at hand must be clarified in itself, done so in a way "so as to solve the difficulties" that belong to the topic, and lastly one must "[make] apparent the cause of the perplexity and of the difficulties about it. For thus most beautifully would each thing be shown" (Aristotle 2004; 211a7-12). We adopt this method in proposing an affirmative answer to our question: Does cosmology need hylomorphism? We begin by introducing the idea of a philosophy of nature $(\S 1)$, and then the various explananda for which any proposed philosophical foundation of cosmology must account, namely, permitting change and process in

\footnotetext{
${ }^{1}$ Contra Dingle 1937; Hawking \& Mlodinow 2012.
} 
the universe $(\S 1.2)$, composition and structure in the universe $(\S 1.3)$, and the resolution of two key philosophical difficulties $(\S 1.4)$. Next, we review various alternative proposals $(\S \S 2.1-2)$ to the recently revived, Neo-Aristotelian school of thought (§2.3). We subsequently defend hylomorphism itself $(\S 3)$, along with two characteristics crucial to cosmology: the unity of complex essences and global emergent properties (§3.4). We then employ these characteristics of hylomorphism to account for the cosmological explananda ( 4$)$, and, lastly, to resolve two key difficulties in the philosophy of cosmology: the meta-law dilemma and the uniqueness of the universe $(\S 5)$. We conclude $(\S 6)$ that cosmology needs hylomorphism.

\section{Explananda and difficulties}

In this essay we assume that cosmology needs philosophy. ${ }^{2}$ However, an incompatible variety of accounts have been offered as to which philosophy it needs. ${ }^{3}$ Generally, a distinction is drawn between philosophical and empirical cosmology (Heller 2011, p. 165), or between cosmologia and cosmology (Ellis 2017, pp. 3-4). This divides "metaphysical" or "philosophical" issues from "scientific" problems and topics, a cut originating with Wolff and Baumgarten and culminating with Kant, whose metaphysical system claimed transcendental priority over any possible empirical inquiry into nature. This divide discounts the possibility of an empirically grounded philosophy of nature that both contemplates the universe antecedent to any of the specific natural sciences and yet is consequently refined by them. In what follows, by

${ }^{2}$ See Rovelli 2018 for a general defense of this idea, and Ellis 2014 for specific defense.

${ }^{3}$ See McMullin 1981, and his 1969 is a review of all possible philosophies of nature; Gale and Urani 1993; Leslie 1999; Heller 2011; Ellis 2006, 2014, 2017; Unger and Smolin 2014, p. xvii. 
"philosophy of nature" or "natural philosophy" we intend such a viewpoint. ${ }^{4}$ It may help us escape the needless dichotomy between mere philosophical reflection and sheer philosophical imposition. Such a philosophy of nature — to bend the terms of Sellars (1963) — would include the scientific image within the manifest image. It would do so if it were the definitive theory of the manifest image insofar as the scientific image is dependent upon it (see Van Brakel 2013, p. 199).

What cosmology needs, as does science in general, is a philosophy of nature that grounds micro-, meso-, and macroscopic scales in the universe as such. For our purposes, we will take "macroscopic scales" to refer to cosmological scales; "microscopic scales" will keep its usual sense. This renormalizing also recognizes mesoscopic individuals as given realities, such as human beings or other animals and things in common experience. Based upon this "middle scale" one may proceed to analyze either their parts at microscopic scales or to their collections at globally macroscopic scales. ${ }^{5}$ Thus, the mesoscopic scale includes paradigmatic examples of substances; the microscopic (cellular or atomic) and macroscopic (cosmic) scales contain mostly parts of substances and aggregates or systems of substances, respectively. ${ }^{6}$ Keeping in mind the distinction between the manifest and the scientific image, a philosophy of nature must begin with

\footnotetext{
${ }^{4}$ We would thus distinguish "philosophy of nature" from "metaphysics" or "first philosophy," as did Aristotle (see Metaphysics, VI.1, 1026a27-32), although such epistemological bookkeeping need not be accepted by readers in order to follow or accept our arguments.

${ }^{5}$ See Tahko 2017; Oderberg 2017, p. 218.

${ }^{6}$ Exceptions at the microscopic scale usually include unicellular organism and free atoms, although the latter are debated by hylomorphists as instances of substances in their own right.
} 
the mesoscopic scale, since it is the most familiar to us at first (Aristotle 2004, 184a16-18). What is the best natural philosophy at this "middle" scale? ${ }^{7}$ Historically, hylomorphism claims this title. Hylomorphism's self-referential coherence also recommends it. The true philosophy of nature cannot propose principles that eliminate the philosopher who proposes the theory; for instance, a sound philosophy of cosmology must be self-referentially compatible with the thinking cosmologist (Ellis 2016, p. 29), who, on a hylomorphic account, exists at the existentially familiar, mesoscopic scale. Since it begins from our metaphysical neighborhood, the hylomorphic analysis requires a hierarchy of applicability so as to coherently ground all scales of natural scientific reflection. It begins in the mesoscopic but must end in scales beyond without reduction or elimination. We aim to apply it on the global scale. Indeed, to show its complete worth, hylomorphism must go global. Will hylomorphism yield philosophical advantages for cosmology ${ }^{8}$ To prepare our answer, we articulate in the remainder of this section the various philosophical marks that any philosophy of cosmology must meet.

\subsection{The philosophical explananda}

We begin by defending the basis for these explananda. As a science, cosmology has a

${ }^{7}$ For recent work on this philosophy of the "middle-sized" or "ordinary" object; see Thomasson 2007, Van Brakel 2013, Boulter 2013, Needham 2017.

${ }^{8}$ The literature on hylomorphism is vast; for the general background to our approach, consider Maritain 1940, 1951, 1955; De Koninck 1959, 1961, 1964, 2008, 2009; Wallace 1996. Brague 2015, p. 37, expresses our concern: "I take here the word 'cosmology' in the meaning that is suggested by its etymology: a logos about the kosmos. Not a description, but some sort of account, an attempt at making sense of it, at deciphering its meaning." 
specific subject, or that about which it is concerned, and argues for various properties of this subject, thereby constituting the object of cosmology, that is, the subject with properties proven of it. The mode of cosmology's argumentation is empirical and physico-mathematical, and its conclusions are argued to with probability. This schema descends from the AristotelianThomistic tradition of the logic of scientific inquiry and is useful for our purposes. ${ }^{9}$

The subject of cosmology is the universe: "Cosmology is the study of the large-scale structure of the Universe, where 'the Universe' means all that exists in a physical sense" (Ellis 2006, p. 1183). The physical universe must be distinguished from the observable universe, for our observational horizon is limited in various ways (ultimately by the last scattering surface; see Ellis 2014, p. 8). However, as even a medieval could recognize, one cannot say without qualification that cosmology studies "all that exists in a physical sense," for this does not distinguish it from the other sciences, such as physics or chemistry. Aquinas's medieval view specified that cosmology studies mutable beings insofar as they constitute those parts of the universe having natural positions or places, which places determine all possible local motions belonging to the elemental, fundamental natures. ${ }^{10}$ Ellis provides the modern specification: largescale structure. This "structure" is intended to pick out the law-governed, spatiotemporal behavior, interaction, and formations of all mass-energy through gravitational forces and the cosmological constant. Hawley and Holcomb provide another specification: "We restrict our

\footnotetext{
${ }^{9}$ On the schema itself, see Aristotle 2014, Posterior Analytics, I.6, 75a29-37; Aquinas 1958, 1989; Maritain 1951; De Koninck 1957. To fill out this schema, we consulted Whitrow 1959, Tolman 1987, Harrison 2000, Hawley and Holcomb 2005, and Ellis 2006, 2014, 2017. ${ }^{10}$ See Aquinas 1886, In De Caelo, lib. 1, lect. 1, nn. 4-5.
} 
definition of cosmology to the study of the formation, structure, and evolution of the universe as a whole" (2005, p. 5). These specifications assume that "the Universe" is a sufficiently stable background concept (a background assumption that is no longer unproblematic, with no small thanks due to Kant; see McMullin 1981, pp. 177-78). Consequently, cosmologists speak of "model universes" as their subject (Whitrow 1959, p. 98; Harrison 2000, pp. 13-15). We conclude, for our purposes, that cosmology's subject is all physical objects, or the universe, insofar as it exhibits law-governed behavior, particularly gravitational interaction and the formation of structures at global spatiotemporal scales, captured in model universes. By "global scales," we mean those commensurate to the universe, which cosmology assumes to exist. Since no science can prove the existence and nature of its own subject, defending the coherence of this assumption is one clear task of the philosophy of cosmology.

The object of cosmology is constituted by cosmologists when they argue for what is true or probably true about the universe as their subject. In order to do so, they make various prior assumptions that yield theoretical outcomes (models), which are used to interpret a data-set of observations. The prior assumptions include, for instance, items taken as established by particle physics, general relativity, chemistry, and various scientific practices (e.g., spectroscopy). The cosmological models predict or explain observable astronomical phenomena (e.g., elemental abundance, cosmic background radiation, the Hubble constant). The standard model of cosmology allows cosmologists to make probable truth claims about the universe: its age, development, structure, its parts and their historical characteristics, its spacetime geometry, and its possible natural fates. Such claims are limited by the nature of the physico-mathematical method. These limitations lend a dialectical status to the standard model (Ellis 2017, p. 22). This status of probable truth is in no small part due to the inquiry's subject: 
The underlying basic problem in studying cosmology is the uniqueness of the universe. There is only one object to look at, and no similar object ${ }^{11}$ to compare it with. Also there is no chance to rerun it in an experiment. This is what makes cosmology unique as a science .... It is a unique historical science, where no direct experiments are possible on the object being investigated as a whole (even though many are possible on parts or aspects of the whole). (Ellis 2014, p. 6)

Any philosophy of cosmology must be able to ground the features of both the subject and object of cosmology, including its status as "a unique historical science." By "grounding" we mean providing an account through principles that make possible the truth of scientific explanations. ${ }^{12}$ In the next two subsections, we detail our explananda based on this subject-object schema.

\subsection{Change \& being}

A changing being is something whose motion is from a start to an end: its being is whencewhither. A moving thing also implicates a subject and a succession of states (possibly a continuum of states). Most philosophical accounts of motion take this basic structure for granted. Thus, we can use it without bias to develop certain explananda of cosmology: law-governed behavior, the conditions of this behavior, and the permitted kinds of behavior.

First, a philosophy of cosmology must provide a foundation for discussing laws at a global scale that capture the behavior of parts of the universe. Cosmological processes have spatial and

\footnotetext{
${ }^{11}$ Note that Ellis uses "object" here in a way that it names the "subject" of cosmology. An object of our experience can also be the subject of an inquiry.

${ }^{12}$ Compare Pruss 2013, pp. 120-21, 132. We further clarify "grounding” in $§ 2$.
} 
temporal features, are thermodynamically and temporally asymmetric, and permit mathematical description. Second, the existence of global initial conditions and constants must be given some account. These initial conditions are necessary in order to give a physical meaning to the mathematical models of cosmology. They also represent characteristics of the actually observed universe that discriminate between alternative model universes. Third, the kinds of processes that are permitted at cosmological scales and their connection with other physical processes must be given some account. This primarily includes processes that form the components of the universe (Big Bang nucleosynthesis and the formation of the principal cosmological objects-nebulae, stars, planets, star clusters, galaxies, and galactic superclusters).

\subsection{Composition \& structure}

Mutable beings also exhibit composition at a time (synchronically) as opposed to over a time (diachronically). Various well-known philosophical problems concern the composition of material objects. Here, we can apply the notions of part-whole composition and the aggregation of individuals to further articulate the explananda of cosmology.

First, the philosophy of cosmology must be compatible with familiar kinds, the ordinary objects of everyday experience (e.g., cosmologists). Second, it must provide a way to see the existence and relationships between local and global structure of physical objects in the cosmos, for cosmology is a theory of the whole that includes all smaller scales as parts in some way and permits their possibility. Third, it must allow for a natural understanding of the kinds of objects permitted in the universe and the makeup of those objects (e.g., galaxies with a certain hydrogen abundance). This is related to the second requirement insofar as cosmology studies aggregates of individuals with ultimate constituents or material parts. Fourth, the sought-after basis must also generally sustain the possibility of spacetime, even apart from specific interpretations of the 
mathematical formalism of special and general relativity, and it must also sustain the possibility of this universe having a particular spacetime structure (e.g., globally flat or curved). Clearly this overlaps topics from $\S 1.2$. However, if space and time are ontologically posterior to the synchronic structure of objects, then the problem of spatiotemporal structure belongs in this category.

The topics arising from the diachronic character of mutable being comprise a first area where hylomorphism can ground cosmology $(\S 1.2)$. The second area is the synchronic features of mutable being (§1.3). Grounding both would provide us with the first overall result in the philosophy of cosmology: an account of the existence of global regularities and structures.

\subsection{Two key philosophical difficulties}

The following two difficulties are some of the specifically philosophical problems that arise in cosmology. They are philosophical since they concern cosmology's presupposed methodology, epistemology, or ontology. While these two are not the only such difficulties, they are central and illustrative test cases. ${ }^{13}$ Can hylomorphism successfully address them?

The first problem concerns the regularity of global regularities. Generally, the possibility of a change of the laws of the universe is recognized by various cosmologists. ${ }^{14}$ This problem leads to the meta-law dilemma articulated by Roberto Unger and Lee Smolin (2014). They defend "temporal naturalism," the view that what exists does so by being contained within time. Nature is a "historic" or time-soaked reality; there is no realm of separate, atemporal laws governing it.

\footnotetext{
${ }^{13}$ Another issue that we do not have space to consider in this essay is the question of how mathematics is applicable to the study of nature. However, see the final argument in $\S 4.2$. ${ }^{14}$ See Bondi 1990, p. 192 and Gale 2011; Barrow and Tipler 1988, p. 255-56.
} 
If everything that exists is subject to change in time, this includes the laws of nature, whether within the history of a given universe or through the succession of "generations" of universes. Now suppose, on the one hand, "that the change of laws of nature is itself governed by laws: higher-order laws or meta-laws. Then the problem of the historicity of nature and of its regularities will simply recur at that higher level" (ibid., p. 275). That is, the regularity of global regularities would defeat their temporal naturalism. However, if there are no higher-order laws governing the change of law-governed regimes, then "it seems that [this change of law-regimes] is uncaused, which is to say arbitrary or at least without explanation, whether deterministic or probabilistic. Then indeed the idea of a history of the universe would have driven us to explanatory nihilism" (ibid.). That is, in the absence of using laws as our sources of explanation in science, the alternative in the meta-law dilemma seems to be scientific irrationality. Is hylomorphism able to escape the meta-law dilemma and ground the regularity of global regularities?

The second problem concerns the existence of the global as such. Typically discussed in terms of a "multiverse," this topic impinges as much upon the models of the universe as it does the nature of the cosmologist's presuppositions about the existing Universe. ${ }^{15} \mathrm{We}$ leave to one side the "many worlds" views deriving from metaphysical interpretations of modality and possible worlds. ${ }^{16}$ A multiverse or "many worlds" is also implicated in the Everettian interpretation of quantum mechanics (see Wallace 2012), which we likewise leave aside. ${ }^{17}$ The

\footnotetext{
${ }^{15}$ See Ellis 2011, 2014; Kragh 2009; Stoeger et al., 2004.
}

${ }^{16}$ See Oderberg 2009 for a convincing critique.

${ }^{17}$ The Everettian thesis does not add anything new to cosmological multiverses as such, but 
multiverse as a cosmological topic is motivated by various scientific problems (e.g., how to explain the precise values of cosmological constants that permit living beings). Objections are raised for and against the uniqueness or multiplicity of the universe based on whether notions of "laws" or "probability," which typically concern sets of individuals, are applicable to the universe as a whole. ${ }^{18}$ The theoretical elaboration of cosmological multiverses is also required by the mathematical models of the inflationary universe hypothesis (see Steinhardt 2011; Guth and Steinhardt 1984). Following Ellis et al. 2004 (pp. 921-22), we will distinguish between "universes" that are causally connected (even if only in the past) from those which are causally disconnected. The latter we will call a para-universe. The former is still one universe, even if it is a certain ensemble or a multi-domain universe, "the one unique connected existing spacetime of which our observed expanding cosmological domain is a part" (ibid., p. 921). ${ }^{19}$ Can hylomorphism successfully address this topic, and ground the global as such?

\section{Alternatives}

Alternative positions in the philosophy of science are sometimes schematized in terms of realists or anti-realists (Chakravartty 2007, p. 10). Others divide the territory between Humeans, semiHumeans, and anti-Humeans (Bird 2010, p. 1-2), or equivalently, between regularity theorists/Humeans, nomic necessitarians/Platonists, and dispositionalists/Aristotelians; (B. Ellis 2002, pp. 1-2; Dumsday 2013, p. 143). Others use the vantage point of the problem of universals

merely extends existing ones into various quantum branches (Tegmark 2003).

${ }^{18}$ See Ellis 2014; Unger and Smolin 2014, Part I, ch. 1, and Part II, ch. 2.

${ }^{19}$ One subsequently asks, qua cosmologist, how a multi-domain model is testable. 
(Peterson 1996). However, these contemporary maps are palimpsests over an older schema (Aristotle 2004, 184b14-20). Aristotle divided approaches with these questions: Do you say that the principles of nature one or many? If they are many, are they finite or infinite in number? ${ }^{20}$

By "principle" we have in mind an analogously applicable notion. A principle is some thing in reality or in our knowledge (e.g., a physical force, a cause, an organic power, a moral agent, a premise, an axiom, an argument) standing first in an order of responsibility for the existence or knowledge of others. It is related to the idea of "ground."

Principle: that first thing from which a thing either exists, comes to be, or is known (see Aristotle, Metaphysics, V.1, 1013a17-20).

To Ground: to be or act as a principle of some thing's being or being known. A principle of nature, therefore, is an origin of being, becoming, and knowledge with reference to the natural world. Natural principles as grounds are of key concern to the philosophical foundation of the sciences.

We now review alternatives for a philosophy of cosmology. While our presentation does not

${ }^{20}$ By using this schema we not only gain a broader view of possible alternatives but can usefully juxtapose contemporary views with older traditions. While Aristotle's schema does not, in places, map neatly onto contemporary ideas, reviving his division and seeing its plausibility will complement our revival and defense of the division's original theoretical target: hylomorphism. Besides, the usefulness of returning to the Greeks for inspiration has been noted before: "In probing the foundations of any domain of contemporary problems — e.g., of physics—one discovers the same structures that the Greek philosophers discovered long ago, if from a different angle" (Weizsäcker 2014, p. 136). 
claim either to do justice to all the substantial details of these alternatives or to refute them definitively, certain difficulties will be raised with each so as to highlight the possible advantages of a complete hylomorphic foundation for cosmology, whose blueprint is our main concern.

\subsection{The new Pre-Socratics?}

We begin with positions that advocate one or indefinitely many principles of nature. Views based upon the "block universe," a seemingly natural interpretation of the mathematics of relativity theory, or the monism of Jonathan Schaffer illustrate the former view. Unger and Smolin are illustrative heirs apparent of the latter view.

The new Parmenideans typically use relativity theory to defend a version of spacetime monism: the universe is fundamentally one thing due to the unified nature of spacetime (Schaffer 2009, 2013). However, strong cases have been made that the block-universe view is undermined by self-referential difficulties if one denies the reality of the passage of time (e.g., Feser 2017, pp. 38-40). Schaffer's own "priority monism"- -his attempt to avoid "existence monism" by not denying that there are other "things" in the world (like you and me), and asserting that these things are instead neither fundamental nor substances—-might indirectly collapse into existence monism if arguments in Tahko 2017 are sound. If it does, this new monism, just like its old counterpart, would fail to permit without eliminativism the existence of global regularities and structures at the micro-, meso-, and macroscopic levels.

Today's new Heracliteans continue the tradition of process metaphysics that draws its inspiration from Heraclitus' unique river; modern variants of such ontologies have been proposed by Hegel, Whitehead, and Peirce. Unger and Smolin (2014) defend a "proto-ontology," that is, not "an ontology in the making" (ibid., p. 239) but a rejection of "the project of establishing any view that represents the world to have an abiding structure, complete with a list 
of the kinds of things that there are and of the ways in which they eternally interact" (ibid., p. 240). Their proto-ontology only assumes reality with plurality. The first means that what exists cannot come from nothing (the non-real), and the second places "otherness" in nature such that it is a principle of change and consequently of time, "a susceptibility to variation or differentiation within the one: the otherwise single and uniform reality" (ibid., p. 241). This "susceptibility" is fundamental and rooted in every aspect of what could be, consonant with their temporal naturalism. In such a universe, the only constant is change; all forms or types are impermanent. Nature's principles are therefore indefinite. The meta-law dilemma is a consequence of this proto-ontology.

\subsection{Hume? Plato?}

Contemporary philosophies that advocate a finite plurality of principles are, generally, three. As mentioned above, the typical division among these alternatives is between the regularity view, the nomic necessitation view, and the dispositionalist view. These have been advanced based upon overarching concerns to account for the laws of nature used by modern science. The first two situate the ground of nature's laws extrinsically to the behaviors and structures in the universe (the grounds proposed are not constitutive of the very being of the behaviors and structures). ${ }^{21}$ The third view situates the ground of laws intrinsically in relation to those behaviors and structures (the ground does constitute their being in some way).

The first view is the Neo-Humean or regularity view of the laws of nature. ${ }^{22}$ This view maintains that "laws are regularities that fit into or may be derived from the optimal

${ }^{21}$ See Heil 2017; Dumsday 2012; Bird 2010, pp. vii, 97; Feser 2014, pp. 69-70.

${ }^{22}$ See Lewis 1983, 1987, 1994, 2001 [1973]. 
systematization of the facts concerning individual things" (Bird 2007, p. 1). This is typically paired with both recombination and Humean supervenience. ${ }^{23}$ Recombination maintains that there are no objective modal connections between existing events in the universe; there is no "inner character" of one event that makes a subsequent event possible (with probability or necessity). Humean supervenience maintains that laws bear a supervenience relation to the mosaic of all such events (which events are usually conceived of in terms of spacetime points). If the regularities of the events differ, so will the laws, and thus the laws are said to supervene upon the mosaic. The laws of nature are our epistemically efficient, factual generalizations about nature and contingently categorical truths.

The second view is a Platonic approach to nature's laws, which is not uncommon among cosmologists. ${ }^{24}$ This view is frequently assimilated, as the more general case, to the nomic necessitation view. ${ }^{25}$ (This latter view is superficially similar to ontic structural realism, or OSR; see French 2014, chs. 5 and 8-9. ${ }^{26}$ ) Nomic necessitation generally maintains that something

${ }^{23}$ See Harré and Madden 1975; Dumsday 2012; French 2014, p. 232; Simpson 2017, p. 125.

${ }^{24}$ Prominent proponents include Roger Penrose or George Ellis.

${ }^{25}$ See Dretske 1977; Tooley 1977. Armstrong 1983, 1997, claims to avoid the charge of Platonism; see Carroll 1994, Appendix A; Dumsday 2013, p. 143; Mumford 2004, p. 91; at least Bird 2010, pp. 51-55, and Feser 2014 p. 70, characterize Armstrong's view about universals as closer to the Aristotelian line. However, insofar as they all fall prey to the third-man objection leveled against Platonism, based upon second-order universals, we consider these views together. ${ }^{26}$ As a basis for the ontological interpretation of relativity theory and thus a possible philosophical ground for cosmology, OSR is critiqued —effectively, in our view—by Feser 2017, 
more must be said about the laws of nature beyond the claims of the regularity theory: "For it to be a law that an F is a G, it must be necessary that an F is a G, in some sense of "necessary", (Armstrong 1983, p. 71). The way to obtain such necessity is by appealing to what ' $F$ ' and ' $G$ ' are. These quiddities of ' $\mathrm{F}$ ' and ' $\mathrm{G}$ ' are universals instantiated in states of affairs; the laws of nature are second-order universal relations between these first-order universals, upon which the second-order relation confers necessity. This nomic necessitation relation is a fundamental, inexplicable reality. ${ }^{27}$ Still, these laws are contingent because the second-order links between first-order universals could have received a different cosmological distribution.

Both of these views have been widely criticized. We will only note certain difficulties pertinent to the philosophy of cosmology. These views have in common the fact that they tend to divorce being from doing. In this respect, both views are modern descendants of occasionalism about the powers and natures of things. ${ }^{28}$ They claim agere non sequitur esse-manifested operations do not follow upon the inner being of a thing. This makes either view prima facie difficult to square with the demands of our cosmological explananda, since the development and existence of interconnected scales is crucial to that scientific inquiry. The being and activity of one scale has the power to affect the very being and activity of things at another scale: e.g., certain distributions of matter and elemental abundances are required for the emergence of life, and so evolutionary processes would be dependent upon cosmological processes.

pp. 47-50. However, since Feser limits himself to special relativity, his critique is also limited. We also must leave aside OSR in this essay, since we do not have the space to do it justice.

${ }^{27}$ See Armstrong 1983, pp. 85-86.

${ }^{28}$ Similar points are made by Bird 2010, pp. vii, 47, and see especially Heil 2017. 
This general cosmological difficulty can be specified. The Neo-Humean's use of recombination requires "that the notion of a change in the course of nature is not selfcontradictory" (Harré and Madden 1975, p. 44). Yet this claim depends, in part, upon a conceptually atomized redescription of events that highlights contingent connections and ignores necessary conceptual links discovered in scientific inquiry (ibid., pp. 44-49). Furthermore, if one adopts the thesis of supervenience, one might undermine the unity to the physical universe to which empirical discoveries of cosmologists attest. If so, the Neo-Humean seemingly has no non-epiphenomenalistic account of the global as such to offer to the cosmologist. ${ }^{29}$

The particular difficulty for the nomic necessitarian's view parallels ancient objections. ${ }^{30}$ If the laws of nature are second-order universals that ground a relation of necessitation between first-order universals, what necessitates the relation of the second-order universals to the first such that this association is itself not a merely contingent regularity? If it is due to a third-order relation of necessitation, a recursion problem results. ${ }^{31}$ Furthermore, if the universe, the global as such, is a state of affairs whose unity is constituted from a hierarchy of such higher-order universal relations that constitute the most global universal laws (Armstrong 1997, p. 267), and yet the ground of this unity is susceptible to an infinite regress, then the universe which cosmologists study is, ultimately, not unified. The universe would be a loose aggregate, only

${ }^{29}$ See Harré and Madden 1975, p. 80.

${ }^{30}$ See Plato, Parmenides 132a-b; Aristotle, Metaphysics 990b15, 1059b5-10. Hence, the problem is generalizable to other versions of Platonism. The other key difficulty is Mumford's “Central Dilemma"; see Mumford 2004, pp. 143-45; Dumsday 2012, p. 116.

${ }^{31}$ Bird 2010, p. 94. 
existing in astronomical appearances. The common lesson from these arguments is that a causal texture to the universe must come from within if the universe is to be and to behave as a universe: agere sequitur esse.

\subsection{Powers, dispositions, and the new Aristotelianism}

As a large family of views, dispositionalism situates the ground of laws intrinsically in things. They do so by maintaining that at least some properties are dispositional: things are disposed to, prone to, or ordered to certain manifestations, behaviors, or acts given certain conditions or stimuli. "Potency" and "power" are reintroduced into nature. Views about powers diverge when asked about how they ground laws. Proponents generally agree that powers underlie the laws of nature but differ on whether one needs laws at all. For instance, Bird defends the existence and explanatory significance of the laws of nature, while Mumford holds that one needs only powers and can dispense with laws; others maintain a middle ground. ${ }^{32}$

Akin to dispositionalism, hylomorphism arises as an analysis of the coming to be and being of physical objects in terms of matter and form. In dispositionalist terms, "form" generally designates a constitutive principle of the actual manifestation of beings, whereas "matter" designates the power or disposition of things. However, hylomorphism is not coextensive with dispositionalism, for it usually entails the defense of a unifying and essential ground of a thing's dispositional properties: substantial form. Furthermore, contemporary hylomorphism is a variety show, ranging between "staunch" and "faint-hearted" versions (Koons 2014). The "fainthearted" versions selectively or completely deny the following: a power ontology, a sparse view of both fundamental entities and powers, and the existence of fundamental essences and

\footnotetext{
${ }^{32}$ See Groff and Greco 2013, p. 3; see also French 2014, p. 248ff.
} 
properties. Staunch hylomorphism defends all three views. Cosmology needs a version of "staunch" hylomorphism, which Koons explains as follows:

To differentiate hylomorphism from materialism, staunch hylomorphists seek to identify a sparse collection of fundamental composite entities or substances, with enough sparseness to rule out coincident substances altogether. Given a powers account of causality, a sparse theory of fundamental things corresponds to a sparse theory of powers and powerbearers. The crucial question for staunch hylomorphists is this: What is the relation between the powers of a whole substance and the powers of its proper parts? (ibid., p. 157)

Koons's question enables one to approach issues related to a hylomorphic account of material composition (e.g., the chemical parts of substances, see Koons 2018b). We are looking for the hylomorphic foundation of cosmology and thus towards an opposing hierarchy of scale, to the globally macroscopic. Therefore, our crucial question is correspondingly different: What is the relation between the powers of a whole substance and the properties of the aggregates or systems of which it is a member? It naturally leads to questions such as the following: Does the universe as such have a "world disposition" or "power"? Why can an aggregation of individual substances be and be studied as a universe? Such questions about the universe are of central importance to any dispositionalist or hylomorphic philosophy of cosmology.

\section{Hylomorphism}

We have reviewed the various alternatives and provided preliminary reasons to prefer 
hylomorphism. More would have to be said to adequately refute the alternatives. ${ }^{33}$ In the interest of presenting a positive account, we turn to a defense of hylomorphism.

\subsection{Motivating hylomorphism}

There are four general motivational accounts for hylomorphism. Each is an answer to a philosophical problem. First, there is the problem of change, also known as the Eleatic paradox (Aristotle 2004, 191a23-34). Second, and closely related to the first, is the problem of diachronic unity (e.g., the Ship of Theseus). Can one thing both change over time and remain the same? Third, we have problems of synchronic unity or composition. If a substance cannot be made out of substances, then in what sense is one material whole composed out of material parts differing in kind? Fourth, there is the problem of the one and the many, under which we include the problem of universals and of the numerical differentiation of things the same in kind. ${ }^{34}$

Of these four, the first is the most fundamental for two reasons. First, the Eleatic paradox is naturally the first paradox among them all. The principle of non-contradiction requires the selfconsistency of our thoughts about reality, and yet we sensibly experience beings that change, which seemingly are what they are not. The Eleatic paradox thus arranges the mind and the senses, our basic cognitive powers, against each other. For this reason, Parmenides' famous poem depicts two paths of thought. ${ }^{35}$ Therefore, this problem must be addressed first in natural philosophy. Consequently, and second, the solution to the Eleatic paradox governs the solution to

${ }^{33}$ In particular, the hylomorphist must address concerns of dispositional monism (Bird 2010) or other versions of hylomorphism; for such replies, see Oderberg 2011, 2013, and Koons 2014.

${ }^{34}$ Koons 2018a helpfully discusses the last three issues.

${ }^{35}$ See Parmenides, Fragment DK B2. 
the other three problems and not vice-versa.

\subsection{Being in time}

We adopt a temporal approach to the Eleatic paradox and motivate hylomorphism from the reality of time or duration. In this sense, we take Heraclitus as our interlocutor and not Parmenides. We stipulate, based on experience, a sum-total or aggregate of enduring objects, or individuals that exist in time. This duration includes all manners of their change. ${ }^{36}$

Implicit in this notion is the requirement for successive otherness. If the objects enduring through time did not do so by successively exhibiting one state that differs from another, they would neither be changing nor enduring through time, which is against the hypothesis.

Furthermore, this succession implies the notion of order, where one state follows after another in sequence. Here we also require a minimal sort of modality: not just anything could follow anything. This is again consonant with experience. ${ }^{37}$

Now, required by the existential duration of things exhibiting otherness is a subject of such otherness. That is, we experience and say that various things are changing. If this were not the case, no thing would be changing, which is against the hypothesis. This invokes the principle of non-contradiction and requires the truth of a predicate ontology: the ways of being are proportioned to ways of being said. ${ }^{38}$

${ }^{36}$ To this a Heraclitean would agree, but object to any implied permanence of those individuals.

${ }^{37}$ It would also be granted by Heraclitus, who posits a logos to the flux of being.

${ }^{38}$ Here the Heraclitean parts company with us; however, see Aristotle, Metaphysics IV.3-4 and Plato 1997, Cratylus, 439c-440e and 439d on the various problems that result. See Aertsen 1987, pp. 16-31, on the medieval notion of the katallel structure of being, summarized in lapidary 
Finally, the successive existential duration of things subject to change must be a continuous existence. That is, the duration of things has no gaps. If there were gaps in the existence of things subject to duration and change, there would be no continuity of subjects, and thus no things would be changing, which is against the implication of the hypothesis just given.

Here the paradox arises. ${ }^{39}$ If changing being implies a subject that is successively other, then how does it remain the same across each state of successive otherness? If it is not the same across each state, then it does not succeed itself and its existence is not continuous. The notion of a thing subject to change appears to be contradictory: "Mobile being must be a being which changes and which does not change." ${ }^{40}$ The nature of a changing subject has existence and at the same time it loses its existence.

\subsection{Hylomorphism, briefly stated}

The resolution to this paradox of changing beings in time is a distinction. It divides the nature or essence of that which endures. ${ }^{41}$ This essence must be determinable by successive states. This essence must also be determinate to being what it is, and thus continuously remaining the same kind of thing (unless radical change destroys it). The principle of determinability or indetermination we call matter; the principle of determination is form. Thus, the changing subject has a determinate existence which is, in another respect, open to what it lacks due to its

fashion by Aquinas 1884, In Phys., III. 5, n. 15: "The modes of being are proportional to the modes of predicating." (Translations of Aquinas our own unless indicated.)

${ }^{39}$ See De Koninck 2008, p. 259.

${ }^{40}$ Ibid.

${ }^{41}$ The following line of argument follows De Koninck 2008, pp. 259-61. 
ability to be determined otherwise at future times. Hence, Aristotle and Aquinas list the fundamental principles of nature as form (determination), matter (indetermination), and privation (lack).

Since our initial stipulation ranged in general over all possible types of change in the total aggregate of changing things, our notions of matter and form are proportionately vague. Therefore, they would have to be specified through more detailed arguments. Indeed, these notions of matter and form must be specified through accounts of accidental and putatively substantial changes, accounts of diachronic and synchronic unity, and an account of numerical individuation and the possibility of universal concepts of common natures, to say nothing of analogous applications of hylomorphic principles to determinate scientific scales of inquiry.

We will call this hylomorphic nature or essence - that intrinsic principle by which something subsists in being - a "cosmic essence" (CE) both to indicate that we aim to draw out how it grounds a philosophy of cosmology and because, due to the original ambit of the problem, CE is compatible prima facie with a whole cosmos subject to change. We note a few basics about CE. First, note that CE contradicts the Neo-Humean's principle of recombination (for form is determinately such over time), the Platonist's extrinsicism (for CE is internal to a substance), and the monist's denial of distinct substances. Note also that $\mathrm{CE}$ is complex by having parts that are ordered to each other as correlative principles of change. These parts thus compose the nature of a substance insofar as nature is a principle of motion and stability or rest (Aristotle, Physics II.1). This correlativity of form and matter also requires that the material part be pure indetermination (otherwise it would be a principle of being determinately such, and not the possibility of any state or manifestation). This material part must also be common to all mutable beings for the same reason. The formal part, as correlative to that potency or determinability, actualizes or 
determines it to be such while not exhausting its potency to be otherwise. That is, the material part of CE is indefinite in its potency, whereas the formal part is finite in its determination. We define this notion as follows:

Cosmic Essence (CE): an essence that is composed of two parts, one part is a principle of determination (form), and the other part is a principle of indetermination (matter); termed "cosmic" because of its compatibility with a universal ambit of change.

We now articulate two key characteristics of CE.

\subsection{Cosmologically crucial features of cosmic essences}

The first characteristic of CE is its determination of a multiplicity of properties by one essence. Traditionally, hylomorphism defends the idea that a nature can ground multiple properties or types of behavior. Call this the idea of a unified complex essence (UCE). ${ }^{42}$ Both common and scientific experience instructs us that different things are capable of sharing some properties while differing in others. Some properties are distinct and yet necessarily linked (e.g., triangular area and a triangle's angle measure), other distinct properties are contingently linked (e.g., having a high temperature and being in a gas phase; social behavior and high cognitive capacity), and some properties might be unique to a type (e.g., rationality). Furthermore, assuming CE, empirical investigation discovers necessary relationships between properties. Some forms of non-living or living being might uniquely have a property and yet share other properties with nearly every other thing in the universe (e.g., being a gravitating object). By contrast, the Parmenidean denies the existence of substances with distinct, ordered sets of

42 See also Oderberg 2007; Dumsday 2010; Gorman 2014. 
properties. Furthermore, a property might primarily characterize a physical being as unique to that kind, while its other secondary, tertiary, etc., properties are common to other natures. ${ }^{43}$ So, UCE permits an order amongst unified sets of properties; such unities and their mutual ordering of properties (e.g., orders of dependency or correlative frequency) must be discovered through empirical investigation. Having a multiplicity of properties allows one "to read off" different domains of laws across the forms of different kinds of things insofar as some domains apply to the commonly held properties whereas others focus on more idiosyncratic properties. ${ }^{44}$ Given that substances exhibit such arrays of properties, we must infer that the formal part of $\mathrm{CE}$ is not limited to determining only one type of property. We define UCE as follows:

Unified Complex Essence (UCE): a cosmic essence (CE) as the ground of a multiplicity of properties (some possibly unique, others common to other substances), which all belong to a substance, are as a set unified by form and made possible by matter, and which are mutually ordered amongst themselves.

Form is at least minimally unified insofar as it is the truthmaker for this set of linked properties (compare Dumsday 2010). However, we further stipulate a stronger, maximal unity: CE and UCE require what was traditionally called the unicity of substantial form. ${ }^{45}$

${ }^{43}$ See Aquinas 1884, In Phys., lib. 2, lect. 1, n. 5: "[Aristotle] adds primarily [to the definition of nature] because nature, even as it is a principle of the motion of composite things, it is not such first. Thus, that an animal falls down is not due to the nature of the animal as such, but due to the nature of the predominant element."

${ }^{44}$ See Larenz 2013, p. 495-96.

${ }^{45}$ This view claims that one substance has only one substantial form, not many. For various 
The second characteristic of CE, in conjunction with UCE, is that it makes possible global emergent properties (GEP). These are properties of large-scale aggregates, in function of the relatedness and coordination of individual substances. This is possible because CE is not the cause of an independent, isolated substance, but joins substances as members to larger wholes if, on UCE, one or many of its properties entail extrinsic relatedness to or determinability by other things. GEP thus runs counter to the Neo-Humean view of supervenience at global scales; it also agrees with critiques of the "pointilliste" grounding of global features upon a spacetime mosaic of points (see Butterfield 2006a, 2006b, 2006c, 2011). ${ }^{46}$ GEP is also opposed to priority monism's view of the universe as the single, fundamental substance. GEP's local-to-global connection rooted in form is, like UCE, an old feature of the hylomorphic account: "Any creature whatsoever subsists in its own being and has a form through which it is determined as to its species and has an order to something else." ${ }^{47}$ First, this connection is clear in instances of natural environments or surroundings, where a thing can act and be acted upon by other things. Second, GEP also permits physical systems (e.g., a system evolving thermodynamically) or biological ones (ecosystems, adaptive niches). Third, among these properties, some might be so common that they are common to all objects on a cosmological scale. Such maximally global

defenses, see Aquinas 1888, ST, Ia, q. 76, a. 4; 1918, ScG, II.58; also Feser 2014, p. 187ff.

${ }^{46}$ However, the hylomorphist must have distinct views about the details; see fns. 48, 49.

${ }^{47}$ Aquinas 1888, ST, Ia, q. 45, a. 7, c. (emphasis ours). According to Aquinas, this relationship between forms eventually constitutes the form of the universe as a whole, including quotidian cases: "A mouse is killed by a cat to preserve the good of the universe. For this is the order of the universe, that one animal lives off another" (Aquinas 2018, Super Mat., X, lect. 2, n. 874). 
properties would not only belong to things in common but also be necessary conditions for constituting a large-scale system of interacting objects (e.g., by being a gravitating object, by being such as to permit interactions that exhibit the conservation of energy). ${ }^{48}$ Thus, GEP is also compatible with the existence of global properties that are also conditions productive of "topdown" effects, either those determining the context for local physical variables or those determining the boundary conditions for isolated systems (see Ellis 2017, pp. 274-86). Finally, GEP incorporates the insight that some aggregates are natural "systems," true unities calling for independent analysis (Clarke 2009; Juarez 2017, p. 11). We define GEP as follows:

Global Emergent Properties (GEP): large-scale properties, that is, properties of aggregates or systems of substances, which properties are grounded locally due to CE and arise globally due to mutual relations or causal interactions on UCE.

GEP, then, is the local grounding, by CE and UCE, of global-scale properties. How exactly GEP obtains in the universe is an empirical question, one that the various sciences investigate. It is also a separate question whether CE and UCE are necessary and sufficient conditions to explain GEP or whether they are merely necessary. That is, it is possible that GEP requires further causes

${ }^{48}$ As critics and proponents of dispositionalism have noted, conservations laws "deserve special attention and, in any case, extra work is needed for their accommodation within the context of [dispositionalism]" (Livanios 2018, p. 70; see also B. Ellis 2001, pp. 205, 249; Bird 2007, pp. 213-215). Since GEP permits the local ontology of hylomorphic substances to be determinable in part by global conditions, conservations principles as features of the coordinated interactivity of physical objects in the cosmos can be accommodated. We plan a separate defense to show in detail how hylomorphism meshes with least action and conservation principles. 
for its own sufficient account (see the end of $\S 5.2$ and $\S 6$ ).

\section{Grounding modern cosmology through hylomorphism}

Hylomorphism, using CE, UCE, and GEP, provides us with a way to meet the cosmological explananda. First, however, the relationship between hylomorphism and motion must be clearly established. CE-style hylomorphism leads one, with little trouble, to Aristotle's definition of motion, or, "the actuality of what exists in potency, as such" $(2004,201 \mathrm{a} 11)$. This definition requires that motion possess a twofold order between a disposition and a manifestation, or the potency and act intended by the definition. Consider a lukewarm object that is disposed to becoming hot. That object is being heated, or is in motion, only insofar as (i) the present act (manifestation) of lukewarmness has an order to a prior potency (disposition) already realized and insofar as (ii) its potency to be hot (a disposition) has a present order to the act (manifestation) of heat not yet gained. In other words, the present act of lukewarmness does not manifest the correlative potency to be lukewarm as such, nor does the present potency have an order to the present act of being lukewarm as such. Once again:

An imperfect act fulfills the definition of motion both insofar as it is compared to a further act as a potency and insofar as it is compared to something imperfect as an act. Thus, motion is neither a potency existing in potency, nor is it an act existing in act, but it is an act existing in potency, (i) such that "act" designates the order of [the mobile] thing to a prior potency, and (ii) such that "existing in potency" designates its order to a further act. (Aquinas 1884, In Phys., lib. 3, lect. 2, n. 3; our numbers)

The temporal structure of motion is readily apparent in this twofold order: the past arises from "a 
prior potency" now manifested, and the future from "a further act" yet to be realized. Thus, not only motion but temporal structure is naturally recovered by this analysis. Furthermore, instead of considering "a motion" as nothing beyond what supervenes on "the occupation" of the moving object at points of space and at moments in time, the hylomorphist grants a unity to a motion between its beginning and end. The hylomorphic account thus defends the continuity of motion (or at least its virtual continuity, in view of quantum mechanics), contrary to "at-at" analyses of motion (classically defended by Bertrand Russell and implicit in the pointillisme of Lewis; see, respectively, McCoy 2018 and Butterfield 2006a, 2006b, 2006c, 2011). ${ }^{49}$

How will this general hylomorphic theory of motion be of service to cosmology? ${ }^{50} \mathrm{By} \mathrm{UCE}$, each moving object can possess a range of types of motions as properties. By GEP, it is possible

${ }^{49}$ A development of the hylomorphic account of the physical continuum, the continuity of motion, and its implications for endurantism and perdurantism is beyond the scope of this essay; on this Aristotelian theory of the continuum, see Hassing 1991, White 1992, and Hellman and Shapiro 2018.

${ }^{50}$ We note below where our hylomorphic account must be articulated with more precision so as to incorporate, into a broadly Neo-Aristotelian framework, the various foundational concepts and current difficulties of classical, relativistic, and quantum mechanics. Regarding the epistemological requirements of this framework, see Cartwright 1989, 1999, and Lanao and Teh 2017. Cartwright (1989, p. 198-99) acknowledges the "traditional metaphysical issues" related to abstraction and the problem of universals at play here; in this respect it is useful to consider whether older theories of abstraction can apply in these contemporary contexts; see Maritain 1995, De Koninck 1957, and Brungardt 2016, 2018. 
that this kind-infused range is global or systematic, although whether or not this obtains and how is something that requires empirical investigation.

\subsection{Change \& being in the universe}

We now turn to discuss how hylomorphism grounds change and being in cosmology (outlined in §1.2). First, something must ground cosmology’s discussion of laws insofar as these imply time-bound behavior. Now, hylomorphism grounds the explanation of regular, time-bound behaviors, and what grounds such behaviors also grounds laws. Hylomorphism can provide such a ground through CE and UCE. First, CE, on the side of form, is a principle that determines a subject's mobility. An object's nature is such a ground insofar as the nature is a principle or ontological measure of the object's motion. ${ }^{51}$ This determination of a mobile subject allows for its various natural motions, which motions in turn possess a temporal structure. Second, UCE implies that a given form may have a range of ways of determining the behavior of an object. An object could therefore exhibit gravitating, thermodynamic, chemical, or biological modes of behavior. Our interest is preeminently with laws of a global scale (see §5.2). Hylomorphism grounds laws, therefore, insofar as the unified complexity of the formal principle of CE grounds modes of determinate behavior over time.

Second, the philosophy of cosmology must ground the existence of global initial conditions and constants. Now, hylomorphism grounds the possibility of individualized and particularized conditions of motion. What grounds such a possibility, however, also grounds the existence of initial conditions and constants. This ground arises from CE and GEP. First, CE on the side of matter entails the individuality of those things subject to motion. That is, changing things must

${ }^{51}$ De Koninck 2008, pp. 377-78. 
possess a particularized set of properties to be in motion: a here, a now, a being situated or positioned in such and such a manner, being arranged with a certain density, etc. Second, GEP permits properties of individual mobile subjects to exhibit global coordination with particular characteristics. For instance, the gravitational or cosmological constants arise due to the coordinated behavior among systems of individual material objects in a universe.

Third, the philosophy of cosmology must ground the kinds of processes that are permitted at cosmological scales and their connection with other physical processes. Now, hylomorphism grounds the relation of individuals to their global aggregates, and this grounds the possibility of various large-scale processes. Hylomorphism provides such a ground due to GEP. This aspect of form as a part of $\mathrm{CE}$ is frequently overlooked: form is not only a principle intrinsically determinative of a thing, but also extrinsically determines it in relation to a larger, potentially cosmic, whole, and allows it to be determined by that ambit. Insofar as, on GEP, the properties of individual objects are coordinated to allow a universe, there can exist cosmological processes.

In relation to all three of these points, notice that $\mathrm{CE}, \mathrm{UCE}$, and GEP are general principles drawn from our experience of a natural order of mutable things. They are still principles of the being of things, but precisely how they are such must be discovered through extensive empirical inquiry. Here we recall the concern at the beginning of $\S 1$, that an empirically grounded philosophy of nature must both contemplate the universe in general, antecedent to any of the specific natural sciences, and yet be consequently refined by them. This consequent refinement is what cosmology provides when it reveals the law-governed behavior, global initial conditions and constants, and types of large-scale processes that exist in the cosmos. Hylomorphism provides an analogical schema to unite these features at a macroscopic or cosmological scale with the hylomorphic grounds of micro- and mesoscopic behavior. 


\subsection{Composition \& structure of the universe}

We now turn to the second set of explananda (§1.3). First, the philosophy of nature that grounds cosmology must permit familiar kinds, the "ordinary objects" of our experience. However, hylomorphism possesses such compatibility outright insofar as it is discovered and argued for in this ambit. This humble basis is what one transfers from the manifest image of the world to the scientific image. For instance, the inferred microscopic behavior of substances is epistemically dependent upon observations of behavior at the mesoscopic scales of our experience. Behavior at both scales is transferred to distant objects at macroscopic, global scales. Examples of such a transfer are the use of spectroscopy and estimates of stellar luminosity.

Second, the philosophy of cosmology must ground the existence and relationships between local and global structure of physical objects in the cosmos. Now, hylomorphism permits the possibility of individuals or systems of individuals at various scales, and this allows it to ground the possibility of variegated global structure. Both UCE and GEP indicate this possibility. The diachronic behaviors in $\S 4.1$ must originate from individuals whose natures and consequent properties are capable of acting in those ways (UCE), and these behaviors can in turn lead to aggregates of such individuals in larger systems (stars, planets, galaxies) that can act in coordinated fashions through gravitation and obeying energy conservation (GEP). Such are the specific characteristics of these aggregates discovered empirically by cosmology.

Third, the philosophy of cosmology must ground the possible kinds of objects in the universe and the makeup of those objects (e.g., hydrogen abundance). Hylomorphism permits both the existence and the possibility of discovery of the kinds and constitutions of individuals and aggregates of individuals. This, in turn, permits an understanding of cosmological kinds and their makeup. Hylomorphism permits the existence of such objects from UCE and GEP as indicated in 
the previous argument. However, it also permits the possibility of knowing such objects and their constitutions insofar as it is explains our interaction with the ordinary objects through which we investigate the cosmos. For instance, our knowledge of hydrogen abundance in the universe is based upon our understanding of the spectroscopic behavior of materials at local scales in laboratories. Insofar as a hylomorphic theory of change and structure applies at such scales and grounds how we can know such objects through the stimulus, action, and interaction with their powers, this also grounds our knowledge at cosmological scales. ${ }^{52}$

Finally, sound cosmological ontology must also sustain the possibility of spacetime.

${ }^{52}$ Hylomorphism at the quantum scale presents unique challenges. Given the scale of application of hylomorphism that we are focusing on, we must prescind from, while acknowledging, the difficulties that the hylomorphic model faces when dealing with the synchronic structure of substances at microscopic, quantum scales. These difficulties are active areas of research among hylomorphists of different schools (e.g., consider Koons 2018b). Our proposals of CE, UCE, and GEP do not require specific conclusions about the hylomorphism of quantum physics, although it does imply a specific approach, viz., that "ordinary objects" at the mesoscopic scale (e.g., human beings, animals) be taken as paradigmatic instances of substances. We follow Eddington (1933, p. 37): "The twoness of two electrons is not completely like the twoness of two apples." Quantum non-locality also poses an as-yet unmet challenge to hylomorphism as a "local" ontology of substances unable to act at a distance. Yet substantial form is not "localized" by spacetime points (which are "local" in a mathematical sense); rather, substantial form is ontologically prior to space and time. Various hylomorphic proposals include W. A. Wallace 1979, 1996; Smith 1999; and Simpson et al. (eds.) 2017. See also Kastner et al., 2018. 
Generally, hylomorphism does entail a spatial and temporal structure to the beings in the universe and even a global structure. Insofar as hylomorphism grounds particular initial conditions for the global aggregate of moving things, it would also permit specific spacetime geometries, since these arise from initial conditions. The nature of space and time, however, require further arguments and cannot be deduced from hylomorphism as a general theory. Various intermediate steps are required, including addressing the application of mathematics to natural, physical objects. A broadly Aristotelian philosophy of mathematics considers mathematical objects to be constituted by mentally abstracting certain formal determinations from the material conditions of mutability. ${ }^{53}$ This account of abstraction would contend that

${ }^{53}$ Maritain 1995; De Koninck 1957; see also Franklin 2014 for a generally Aristotelian approach. This view proposes a theory of mixed or subalternate sciences which claims that mathematical principles stand as form to the matter of natural scientific considerations; see Aquinas 1958; Mullahy 1946. It would require a longer excursion to examine how the manner of conceiving things and (recursively) conceiving concepts influences the foundations of modern mathematics and its physical applications, in this case, regarding the nature of spacetime. Such a conceptual "desedimentation" regarding mathematics is undertaken by Klein 1992, and see Hassing 2017; Klein's approach is applied to the ontology of spacetime by Cosgrove 2018. Hylomorphic and dispositionalist accounts of spacetime have been proposed: see Feser 2017 and Bird 2017. The theoretical cost adopting a privileged present, contrary to the demands of relativity, is absorbed by Unger and Smolin 2014 (see pp. 183-84, pp. 386-88) by appealing to a "shape dynamics" approach to gravity, one that recovers relativistic mechanics while maintaining a privileged present; see Mercati 2018 for more. It is unclear whether the same 
hylomorphism is the ground from which mathematical physics has clandestinely harvested many fruits. ${ }^{54}$

Keeping in mind the qualifications made above (that these general principles must be specified by empirical research), we can now say that hylomorphism grounds global regularities and structures. CE, UCE, and GEP give us a way to see the universe as a system of substances which exhibit various scales of law-governed behavior, whose smaller scales feature as parts or members in the behavior and structure at larger scales. However, one qualification is that our application of hylomorphism is limited by the present state of scientific development. This is indicated by the lack of an accepted theory of quantum gravity. Another indication is the "cosmological constant problem." 55 These highlight the tentative state of our cosmological theories, and consequently the current reach of hylomorphism.

\section{Resolutions to philosophical problems in cosmology}

Thus far, hylomorphism has grounded the various cosmological explananda from $\S \S 1.2-3$, fleshing out our positive account. What about the two difficulties from $\S 1.4$ ?

\subsection{The meta-law dilemma}

theoretical escape route is available to hylomorphism, which typically also defends a type of presentism.

${ }^{54}$ Larenz 2013, pp. 496-97.

${ }^{55}$ Some unknown factor prevents quantum vacuum energy in the universe from attaining its predicted value that is $10^{120}$ greater than the observed one, yet that unknown does not eliminate effects of dark energy at global scales (see Peebles and Ratra 2003, pp. 561-62). 
Hylomorphism provides the means to avoid the meta-law dilemma as follows. ${ }^{56}$ First, any change in the global regime of laws is structured by general principles of change. However, these general principles of change are hylomorphic. Thus, any change in the regime of laws is hylomorphic. Consequently, hylomorphism can defend the regularity of global regularities and avoid the "explanatory nihilism" of the meta-law dilemma. Let us expand on this argument.

Unger and Smolin's own discussion of the meta-law dilemma advances four key ideas: possibility landscapes, the adjacent possible, cosmological natural selection, and causal continuity. Borrowing language from evolutionary biology, they propose that regime-changes of laws may occur in the universe's history, and these regimes travel a "possibility landscape" of such regimes, analogous to how species evolve across evolutionary landscapes by exploring the "adjacent possibilities" available to them. The adjacent possible is "what [a phenomenon] can become next, given what it is then." ${ }^{, 57}$ Our current regime of laws is therefore explained by a process of "cosmological natural selection" over this landscape. This invokes causal continuity:

Causation always involves the force of sequence: the shaping of a before on an after. It need not always require that this shaping by sequence assume regular and recurrent form (ibid., pp. 293-94).

This sequence has a "form," just not one that is mathematically law-like ("regular and recurrent"). Now, in order to avoid the first horn of the meta-law dilemma, Unger and Smolin's causal continuity and adjacent possibility cannot itself be law-governed. This "shaping by sequence" is not mathematizable as are the present universe's laws. However, to avoid the

\footnotetext{
${ }^{56} \mathrm{We}$ grant for the sake of argument that the universe does exhibit law-regime changes.

${ }^{57}$ Unger and Smolin 2014, p. 27, and see pp. 245, $301 \mathrm{n}$.
} 
second horn of the dilemma, the changes in the regime of laws, "the adjacent possible," and "causal continuity" cannot imply nominalism. Our concepts must describe real features of the universe, even if those are changeable features. Causal continuity is still intelligible because "in nature, as we observe it, what comes before always shapes what comes later, even if the mechanism of influence may change" (ibid., p. 279). This describable causal influence even persists through time and in extreme states of energy and density, for while "the range of the adjacent possible may be large, the before may nevertheless continue to influence the after in time. Causality survives laws" (ibid., 287; our emphasis). In other words, the causal capacity of the universe is one of its unchanging features, like Heraclitus's logos.

Let us call this causal continuity's shaping, finitude, and persistence a "causal form." Now, it does appear from some passages that Unger and Smolin are nominalists: "As each event and each causal link is unique in the history of the universe, they make up a vast set, when fully described" (Unger and Smolin 2014, p. 383). In the absence of common natures, is not pure history the only alternative? If so, this "causal form" appears to be a very weak claim. Yet Unger and Smolin insist on a real influence between stages where different laws are operative. If these distinct stages exhibit causal continuity, then this requires that features of the prior stage affect the features of the posterior stage. Thus, causal continuity and the adjacent possible must be marked by a causal form that provides finitude and limitation between the various stages of physical laws. That is, not only does this causal form ground nature's intelligibility, it also does so by providing contours to the phenomena and their laws that come-to-be in the new regime. Even if the laws were to change drastically, causality survives laws. Causality is ontologically prior to law and serves as the ground of possibility for law. Thus, Unger and Smolin must maintain that the "adjacent possible" is somehow contained within the prior stage by being 
causally related to the existence of the posterior stage.

Why does this analysis deserve to be characterized as hylomorphic? First, the causal form required — as difficult as it may be to investigate empirically—is a certain ground of intelligibility in things. Second, this causal form provides contours to the conditions, behaviors, and laws in the universe and its stages. Finally, this causal form cooperates with a type of possibility by which successive regimes of laws come into being. However, an innate cause of the intelligibility, determinate actuality, and the limiting principle to potentiality in nature are hallmarks of the formal cause. The analysis is hylomorphic. Our response becomes stronger by looking to GEP. This character of hylomorphism allows that a regime-changing meta-law is a deeper aspect of the universe's nature, permitted by the fundamental matrix of universal potency that constitutes one part of CE. Due to GEP, new regimes of law are contained at the global level in potency and made determinate when a new regime of global form comes to be. Consequently, a hylomorphic analysis can shore up the regularity of global regularities, even amidst putative regime changes in the very laws of nature, and avoid the meta-law dilemma. ${ }^{58}$

\subsection{The one universe}

If GEP implies that the overall form of the universe permits regime-changes to its laws, then something about the existence of the global as such and its kind must be said. Hylomorphism grounds cosmology's assumptions about the unity of the universe, its uniqueness, and, finally, its type or form. Here we consider such arguments from the philosophy of nature; metaphysical

${ }^{58}$ A position akin to Armstrong's could appeal to higher-order universal relations, however, see Lange 2008 against this; the discussions of Armstrong 1983, pp. 22-23, and Lange 2008, pp. 8890, suggest that the regularity view of laws could not avoid the meta-law dilemma. 
arguments for or against a multiplicity of universes are a separate concern. ${ }^{59}$

First, the universe is one or unified. ${ }^{60}$ This is because the universe is an aggregate of material substances exhibiting coordinated interactivity. The coordinated interactivity arises due to both causal and topological connections permitted by GEP. Observations into the universe's past indicate that the observable universe is causally connected. If portions of the unobservable, physical universe are causally separate now, but were not in the past, they count as part of the one universe (a "multi-domain" universe). Such causal connections are permitted by the physical topology of the universe, which cosmologists contemplate via the spatiotemporal structure of general relativistic models whose equations capture how mass and energy are permitted to interact in spacetime. Now, if the aggregate of individuals in the universe exhibits such coordinated interactivity, it forms a unified whole of individuals, a system, for what acts as one exists as one in some sense of "one." Here, the relevant sense of "one" is the unity that belongs to the order of numerically distinct substances. This argument stakes hylomorphism's claim against both monism and a Neo-Humean view; it concludes that the universe is unified.

Second, the universe is unique or one in number. Multiverse claims possess prima facie plausibility insofar as types (e.g., "universe") can receive different instantiations (e.g., "this universe" or "that universe"). ${ }^{61}$ While a distinction of this sort is not logically impossible, it

\footnotetext{
${ }^{59}$ Some cosmologists recognize that there are such arguments proper to natural philosophy in this sense (Unger and Smolin 2014), or at any rate arguments that are closer to the sciences on this topic (Ellis 2014, pp. 11-13).

${ }^{60}$ See also Juarez 2017 for a similar argument.

${ }^{61}$ Compare Aristotle, De Caelo I.9.
} 
might be that it is physically impossible. This would be the case if the universe, as an aggregate of individuals, is composed of all available matter, that is, if the potency for instantiation is exhausted. A universe composed of all available matter would be unique, for there would be no matter to instantiate another instance of its kind. Now, on the strength of the conclusion about the unity of the universe due to its causal and topological connectedness, the present universe-even if a multi-domain one-does contain all available matter. In other words, if there were matter (mass-energy) that were neither causally nor topologically connected of its nature to the present universe, then such matter-if "matter" is not pure equivocation in that case - as causally and topologically disjoint could not be contemplated by the principles of cosmology. ${ }^{62}$ Such matter in putative para-universes is not a physical possibility in the sense that countenancing such possibilities lies outside the scope of cosmology. ${ }^{63}$ Hylomorphism grounds this reply insofar as material potency is the disposition for singulars, a principle of numerical individuation: "Those who speak of 'heaven' speak of the form, but those who speak of 'this heaven' speak of form in matter." 64 Now, the logical possibility of para-universes lies beyond the scope of cosmology as a science or hylomorphic natural philosophy; it is a metaphysical issue.

${ }^{62}$ Aristotle also argues from the causal and physical-topological unity of the universe to its numerical unity (see De Caelo I.8); however, his universe's topology lacked extensive symmetries (it had one spherical boundary with one center); see Jammer 1993, pp. 219-21; Earman 1989. However, the spirit of his argument seems sound.

63 This is echoed by many critiques of the multiverse (para-universe) hypothesis; for instance, see Ellis and Silk 2014.

${ }^{64}$ Aquinas 1886, In De Caelo, lib. 1, lect. 1, n. 2 
Third, hylomorphism can articulate the form belonging to the universe, for this form is constituted through the types of coordinated interactivity of the natures composing that form. Let us contrast this with two other views. On the one hand, Schaffer's monism could also defend an "essence" for the universe - it would be identical with the one and only substance that obeys the fundamental laws of physics. Such an essence could be spelled out, on his view, by appealing to the global behavior that is captured by fundamental physics. On the other hand, and in a quite different way, a Neo-Humean could claim that a single description of the universe at its broadest scale through the global laws supervening upon the total mosaic of spacetime points describes the "essence" of the world. However, if one does not wish to "go fully global" in either of these ways, what could one say?

Perhaps the law-like behavior exhibited by the universe-e.g., as captured in conservation principles - supervenes on or is emergent from the dispositions of individual objects. Brian Ellis suggests that such conservation laws are "of the essence of the global kind in the category of objects or substances" (Ellis 2005, pp. 91-92). So, global behaviors are manifestations of a global disposition that constitutes the essence of the world, independent of individual objects. Chakravartty (forthcoming) proposes something similar: "Why not think of the relevant dispositions regarding conservation as properties of the system itself, as opposed to properties of the things constituting or inhabiting it?" In this sense, conservation laws would be properties belonging to the world itself as a system, properties which are in some sense necessary conditions for local processes. Bigelow, Ellis, and Lierse 1992 conclude that "conservation laws are best understood as ascribing properties to the world as a whole, properties which are essential to the natural kind to which our world belongs" (p. 385). However, they also suggest that this global essence may depend in part upon individual things: "Essences of things in the world, and 
correlations which depend on the essences of such things, may both contribute to the essence of the world as a whole" (ibid., p. 386; see p. 372).

Hylomorphism motivates a similar conclusion since the forms of individual substances are not intelligible and are not causes in isolation, but are intelligible causes relating types of individuals to each other as parts of a larger whole. (The difficulty of achieving this view of the whole explains the appeal of a Neo-Humean position countenancing recombination at globally supervening scales.) This conclusion is permitted by UCE and GEP, and it is empirically supported through investigations into the behavior and development of large-scale systems and biological organisms at cosmological and geological timescales. Thus, the forms of individuals are - via essential, extrinsic, and determinable relations - formal parts of a cosmic whole. Hylomorphism is able to provide a philosophical ground for the universe having its own form through GEP, since this allows us to contemplate a type that contains as defining elements the interconnected dispositions and behaviors of its parts or member substances. This comports with the thesis of past hylomorphists that the form of the universe - the natural kind of the world - is the very unity of order of the kinds of mutable beings constituting it. ${ }^{65}$

Consequently, hylomorphism is the basis for cosmology's ability to study the global as such and of its being a science about a unique historical totality, for it grounds the possibility of studying a total, unique, and unified object, the universe. Hylomorphism does this insofar as it argues that the universe is unified and unique. It can also argue to this conclusion from the connectedness of the micro-, meso- and macroscopic scales, taking as a basis in this regard the

\footnotetext{
${ }^{65}$ See Aquinas 1918, ScG, II.39: "The form of the universe consists in the distinction and order of its parts." These "parts" are primarily kinds and secondarily individuals; see Blanchette 1992.
} 
typical view among scientists and some philosophers that the universe's history is characterized by an increase in complexity. ${ }^{66}$ On a hylomorphic view of this development, it is arguable that the cosmos would have begun in a state of substantial simplicity, and out of this initial composite more complex beings and structures came to be ${ }^{67} \mathrm{Put}$ another way, if it is the case that the initial conditions of the universe at quantum scales included fluctuations of matter "magnified" through inflation to make the seed perturbations that caused the beginnings of large-scale structure formation throughout the universe, eventually leading to the conditions for life (see Ellis 2016, pp. 276-80), then the universe from its earliest stages is connected on all scales through this causal process, which at later times permits the observed complexity at all scales, especially that of living things. However, hylomorphism grounds the analogical unity of all these scales. Hylomorphism, therefore, allows the total global aggregate of mutable substances to be the unique unified system, the cosmos.

However, what justifies our use of "total" in the previous paragraph? Or, to recall the problem from $\S 1.1$, what allows us to speak of "the Universe" as the fundamental background concept in cosmology? We noted at the outset of this section that the topic of the universe is discussed here from the perspective of natural philosophy, not metaphysics. A defense of the existence and intelligibility of "the Universe as such" is a metaphysical issue, in the sense that one doubting either or both would be doubting the very domain of discourse and principles that both natural philosophy and cosmology must assume but neither can defend. Consequently,

\footnotetext{
${ }^{66}$ For instance, see Prigogine and Stengers 1984; Chaisson 2001 and 2005; Novo et al. 2018; Maritain 1997; De Koninck 2008.

${ }^{67}$ See De Koninck 2008, pp. 284, 297-98, 314; Dumsday 2011; Koons 2018b, p. 162.
} 
Aristotle placed the burden on metaphysics to defend the assumptions of the particular sciences (Physics I.2; Metaphysics IV.1). This is also a metaphysical topic due to the nature of the arguments one would have to make. Consider how Aquinas, apart from Aristotelian natural philosophical arguments, defended the uniqueness of the universe against objections that a "multiverse" was possible. These arguments involve lines of reasoning that are clearly metaphysical: e.g., causal regress arguments to God or discussions of God's activity. ${ }^{68}$ In like fashion, the final coherent vision of why the cosmos is one or why there is an ordering of the parts of the universe to each other, and not just that it is so, as grounded above by hylomorphism, would involve one in classical regress arguments about efficient and teleological causes. Such arguments are favored by hylomorphists who are also theists, noting that both the unity of the cosmos (Juarez 2017) as well as the diversity of kinds in the universe call for explanation. As to the latter, theists even propose to explain such diversity in terms of a "quasi-deduction" of the order of the universe. ${ }^{69}$ (Such arguments shed light on the plausibility of Platonic grounds for the

${ }^{68}$ See Aquinas 1884, In De Caelo, lib. 1, lect. 19, n. 197. Aquinas argues that the uniqueness of the world could be inferred from the oneness of its First Mover; he argues that its uniqueness follows from its unified order to the First Mover as an end; he argues that, even were God able to make para-universes, this would either be contrary to his wisdom (if they were wholly alike) or the complete set of such universes would itself be the universe (if they each exhibited diverse perfections); and he argues that the essence of the world and its goodness is "more powerful" in its own kind by being one and not many in number.

${ }^{69}$ Just such a theistic "quasi-deduction"- - the name is from Geiger 1953, p. 397, n.—of the universe from the nature of divine causality is proposed by Aquinas 1926, ScG, III.97. 
philosophy of cosmology, insofar as natures's laws originate as ideas in the mind of God.) We conclude that if one wishes to defend the existence of the Universe as such in the sense of why it exists as it does, metaphysical arguments are necessary. Metaphysical truths and realities, and the cogency of our grasp of the same, ground even the hylomorphic foundations of cosmology presented here.

\section{World enough and form}

We conclude that cosmology needs hylomorphism. This is because hylomorphism is able to ground global regularities and structures, the regularity of global regularities, and the existence of the global as such. It does this by accounting for changing substances with cosmic essences (CE) and thus aggregates of substances, the various scales and domains of law-governed behavior rooted in the natures of those substances (UCE), and how those substances as parts relate to the universe as a unique, unified whole (GEP). It also resolves philosophical problems that arise in cosmology and shores up the cosmologist's intuition of studying a unique, unified totality with an fascinating, intelligible history. Given hylomorphism's close affinity with teleology (in Aristotelianism) and with theism (in Thomism), one might also expect that arguments along these lines could be developed. However, these must be the concerns of other essays. ${ }^{70}$ At present, we hope to have sufficiently drawn up the blueprints to the hylomorphic foundations for the philosophy of cosmology. Hylomorphism initiates the local natural philosophy of the non-living, the living, and even the human being, the mikrokosmos. It is likewise able to ground the natural philosophy of the cosmos.

\footnotetext{
${ }^{70}$ Consider Peterson 1996 and Dumsday 2012; Beltrán 2001 and 2016.
} 
46 of 53 


\section{Acknowledgements}

This paper was produced as part of the author's postdoctoral research project, supported by a grant from CONICYT, FONDECYT, Postdoctoral Proj. No. 3170446. The author gratefully acknowledges this financial support and the faculty and staff of his home institution, Pontificia Universidad Católica de Chile, Instituto de Filosofía. Research for this paper was also conducted at the University of Notre Dame, as a guest of the John J. Reilly Center for Science, Technology and Values and the Jacques Maritain Center, and the author thanks Anjan Chakravartty, John O'Callaghan, and their staff for their support and hospitality during that visit. The two anonymous reviewers also receive the author's thanks for their substantive and insightful comments, which have helped to improve the paper tremendously. The author also gives thanks to many others for their comments, conversations, and suggestions for this paper and its topics, while retaining all blame for remaining errors: José Tomás Alvarado, Oscar Leon, Fr. Phillip Neri Reese OP, Martin Beers, Fr. Thomas Davenport OP, Ryan Shea, Nicholas Teh, Anjan Chakravartty, Jack Cahalan, Matthew Minerd, Marco Stango, Andrew Seeley, Marina Brungardt, and the attendees of the 2017 IIo Congreso Latinoamericano de Filosofia Científica and the 2017 Meeting of the American Catholic Philosophical Association for their comments on predecessor versions of this paper. Finally, in thanks for her insights into cosmology that have helped his own thinking, the author dedicates this paper to Dr. Carol Day. 


\section{References}

Aertsen, J. (1987). Nature and creature: Thomas Aquinas's way of thought. Leiden/New York: BRILL.

Aquinas, S. T. (1884). Opera omnia iussu Leonis XIII P. M. edita, t. 2: Commentaria in octo libros Physicorum Aristotelis (Vols. 1-50, Vol. 2). Romae: Ex Typographia Polyglotta S. C. de Propaganda Fide.

Aquinas, S. T. (1886). Opera omnia iussu Leonis XIII P. M. edita, t. 3: In libros Aristotelis De caelo et mundo expositio; In librum primum Aristotelis De generatione et corruptione expositio (Vols. 1-50, Vol. 3). Romae: Ex Typographia Polyglotta S. C. de Propaganda Fide.

Aquinas, S. T. (1888). Opera omnia iussu Leonis XIII P. M. edita, t. 4: Pars prima Summae theologiae qq. 1-49 (Vols. 1-50, Vol. 4). Romae: Ex Typographia Polyglotta S. C. de Propaganda Fide.

Aquinas, S. T. (1918). Opera omnia iussu Leonis XIII P. M. edita, t. 13: Summa contra gentiles (libri primus et secundus) cum commentariis Francisci de Sylvestris Ferrariensis. Romae: Typis Riccardi Garroni.

Aquinas, S. T. (1926). Opera omnia iussu Leonis XIII P. M. edita, t. 14: Summa contra gentiles (liber tertius) cum commentariis Francisci de Sylvestris Ferrariensis. Romae: Typis Riccardi Garroni.

Aquinas, S. T. (1958). The division and methods and the sciences: Questions V and VI of his commentary on the "De Trinitate" of Boethius. (A. Maurer, Trans.) (2nd ed.). Toronto: The Pontifical Institute of Mediaeval Studies.

Aquinas, S. T. (1989). Opera omnia iussu Leonis XIII P. M. edita, t. 1 */2: Expositio libri Posteriorum (2nd ed., Vols. 1-50, Vol. 1*/2). Roma-Paris: Commissio Leonina-J. Vrin.

Aristotle. (2004). Physics, or natural hearing. (G. Coughlin, trans.). South Bend, IN: St. Augustine's Press.

Aristotle. (2014). The complete works of Aristotle: The revised Oxford translation, one-volume digital edition. (J. Barnes, Ed.). Princeton, NJ: Princeton University Press.

Armstrong, D. M. (1983). What is a law of nature? Cambridge: Cambridge University Press.

Armstrong, D. M. (1997). A world of states of affairs. Cambridge/New York: Cambridge University Press.

Beltrán, O. (2001). El principio antrópico y la interpretación teleológica del universo. Teología, 78(2), 169-208.

Beltrán, O. (2016). Principio antrópico. In (C. E. Vanney, I. Silva, \& J. F. Franck, Eds.)Diccionario Interdisciplinar Austral. http://dia.austral.edu.ar/Principio antrópico. Accessed 21 November 2018.

Bigelow, J., Ellis, B., \& Lierse, C. (1992). The world as one of a kind: Natural necessity and laws of nature. The British Journal for the Philosophy of Science, 43(3), 371-388.

Bird, A. (2007). Nature's metaphysics: Laws and properties. Oxford/New York: Oxford University Press.

Bird, A. (2017). Manifesting time and space: Background-free physical theories. In J. D. Jacobs (Ed.), Causal powers (pp. 127-138). Oxford: Oxford University Press.

Blanchette, O. (1992). The perfection of the universe according to Aquinas: A teleological cosmology. University Park, PA: Pennsylvania State University.

Bondi, H. (1990). The cosmological scene 1945-1952. In B. Bertotti, R. Balbinot, S. Bergia, \& 
A. Messina (Eds.), Modern cosmology in retrospect (pp. 189-196). Cambridge: Cambridge University Press.

Boulter, S. (2013). Metaphysics from a biological point of view. New York: Palgrave Macmillan. Brague, R. (2015). On the need for a philosophy of nature and on Aquinas's help in sketching one. Proceedings of the American Catholic Philosophical Association, 89, 35-43.

Brakel, J. van. (2013). Philosophy of chemistry: Between the manifest and the scientific image (reprint ed.). Leuven: Leuven University Press.

Brungardt, J. G. (2016). Charles De Koninck and the Sapiential Character of Natural Philosophy. American Catholic Philosophical Quarterly, 90(1), 1-24.

Brungardt, J. G. (2018). St. Thomas and Modern Natural Science: Reconsidering Abstraction from Matter. In C. A. Casanova G. and I. S. del Pozo (eds.), Cognoscens in Actu Est Ipsum Cognitum in Actu: Sobre Los Tipos y Grados de Conocimiento (pp. 433-71). Santiago: RIL Editores.

Butterfield, J. (2006). The rotating discs argument defeated. The British Journal for the Philosophy of Science, 57(1), 1-45.

Butterfield, J. N. (2006). Against pointillisme about geometry. In F. Stadler \& M. Stöltzner (Eds.), Time and history: Proceedings of the 28th International Ludwig Wittgenstein Symposium, Kirchberg am Wechsel, Austria 2005 (pp. 181-222). Walter de Gruyter.

Butterfield, Jeremy. (2006). Against pointillisme about mechanics. The British Journal for the Philosophy of Science, 57(4), 709-753.

Butterfield, Jeremy. (2011). Against pointillisme: A call to arms. In D. Dieks, W. J. Gonzalez, S. Hartmann, T. Uebel, \& M. Weber (Eds.), Explanation, prediction, and confirmation (pp. 347-365). Springer Netherlands.

Carroll, J. W. (1994). Laws of nature. Cambridge: Cambridge University Press.

Chaisson, E. J. (2001). Cosmic evolution: The rise of complexity in nature. Cambridge, MA: Harvard University Press.

Chaisson, E. J. (2005). Epic of evolution: Seven ages of the cosmos. New York: Columbia University Press.

Chakravartty, A. (2007). A metaphysics for scientific realism. Cambridge: Cambridge University Press.

Cosgrove, J. K. (2018). Relativity without spacetime. New York, NY: Springer Science+Business Media.

De Koninck, C. (1957). Abstraction from matter (I): Notes on St. Thomas's prologue to the Physics. Laval théologique et philosophique, 13(2), 133-196.

De Koninck, C. (1959). Natural science as philosophy. Culture, 20(3), 245-267.

De Koninck, C. (1961). The unity and diversity of natural science. In V. E. Smith (Ed.), The philosophy of physics (pp. 5-24). New York: St. John's University Press.

De Koninck, C. (1964). The hollow universe. Québec: Presses de l'Université Laval.

De Koninck, C. (2008). The writings of Charles De Koninck: Volume one. (R. McInerny, Ed. \& trans.). Notre Dame, IN: University of Notre Dame Press.

De Koninck, C. (2009). The writings of Charles De Koninck: Volume two. (R. McInerny, Ed. \& trans.). Notre Dame, IN: University of Notre Dame Press.

Dingle, H. (1937). Modern aristotelianism. Nature, 139, 784-786.

Dretske, F. I. (1977). Laws of nature. Philosophy of Science, 44(2), 248-268.

Dumsday, T. (2010). Natural kinds and the problem of complex essences. Australasian Journal of Philosophy, 88(4), 619-634. 
Dumsday, T. (2011). Why Thomistic philosophy of nature implies (something like) Big-Bang cosmology. Proceedings of the American Catholic Philosophical Association, 85, 69-78.

Dumsday, T. (2012). Have the laws of nature been eliminated? In G. Butera (Ed.), Reading the cosmos: Nature, science, and wisdom (pp. 111-128). Washington, DC: The Catholic University of America Press.

Dumsday, T. (2013). Laws of nature don't have ceteris paribus clauses, they are ceteris paribus clauses. Ratio, 26(2), 134-147.

Earman, J. (1989). World enough and space-time: Absolute vs. relational theories of space and time. Cambridge, MA: MIT Press.

Eddington, S. A. S. (1933). Physics and philosophy. Philosophy, 8(29), 30-43.

Ellis, B. (2001). Scientific essentialism. Cambridge: Cambridge University Press

Ellis, B. (2002). Philosophy of nature: A guide to the new essentialism. McGill, Queen's University Press.

Ellis, B. (2005). Katzav on the limitations of dispositionalism. Analysis, 65(1), 90-92.

Ellis, G. F. R. (2006). Issues in the philosophy of cosmology. In Jeremy Butterfield \& J. Earman (Eds.), Philosophy of physics (Handbook of the philosophy of science) (pp. 1183-1284). Amsterdam/Oxford: North Holland.

Ellis, G. F. R. (2011). Does the multiverse really exist? Scientific American, 305(2), 38-43.

Ellis, G. F. R. (2014). On the philosophy of cosmology. Studies in History and Philosophy of Science Part B: Studies in History and Philosophy of Modern Physics, 46, 5-23.

Ellis, G. F. R. (2016). How can physics underlie the mind?: Top-down causation in the human context. Berlin/Heidelberg: Springer.

Ellis, G. F. R. (2017). The domain of cosmology and the testing of cosmological theories. In K. Chamcham, J. Silk, J. D. Barrow, \& S. Saunders (Eds.), The philosophy of cosmology (pp. 3-39). Cambridge: Cambridge University Press.

Ellis, G. F. R., Kirchner, U., \& Stoeger, W. R. (2004). Multiverses and physical cosmology. Monthly Notices of the Royal Astronomical Society, 347(3), 921-936.

Ellis, G. F. R., \& Silk, J. (2014). Scientific method: Defend the integrity of physics. Nature, 516, 321-323.

Feser, E. (2014). Scholastic metaphysics: a contemporary introduction. Neunkirchen-Seelscheid: Editiones Scholasticae.

Franklin, J. (2014). An Aristotelian realist philosophy of mathematics: Mathematics as the science of quantity and structure. New York: Palgrave Macmillan.

French, S. (2014). The structure of the world: Metaphysics and representation. Oxford/New York: Oxford University Press.

Gale, G. (2017). Cosmology: Methodological debates in the 1930s and 1940s. In E. N. Zalta (Ed.), The Stanford Encyclopedia of Philosophy (Summer 2017.). Metaphysics Research Lab, Stanford University. https://plato.stanford.edu/archives/sum2017/entries/cosmology30s/. Accessed 21 November 2018.

Gale, G., \& Urani, J. (1993). Philosophical midwifery and the birthpangs of modern cosmology. American Journal of Physics, 61(1), 66-73.

Geiger, O.P., L. B. (1953). La participation dans la philosophie de S. Thomas d'Aquin (2nd ed.). Paris: Librairie Philosophique J. Vrin.

Gorman, M. (2014). Essentiality as foundationality. In D. D. Novotný \& L. Novák (Eds.), NeoAristotelian perspectives in metaphysics (pp. 119-137). New York/London: Routledge.

Groff, R., \& Greco, J. (Eds.). (2013). Powers and capacities in philosophy: The new 
Aristotelianism. New York/London: Routledge.

Guth, A., \& Steinhardt, P. J. (1984). The inflationary universe. Scientific American, 250(5), 116128.

Harré, R., \& Madden, E. H. (1975). Causal powers: A theory of natural necessity. Lanham, MD: Rowman \& Littlefield.

Harrison, E. (2000). Cosmology: The science of the universe (2nd ed.). Cambridge: Cambridge University Press.

Hassing, R. F. (1991). Thomas Aquinas on Physics VII.1 and the Aristotelian science of the physical continuum. In D. O. Dahlstrom (Ed.), Nature and scientific method (Vol. 22, pp. 127-157). Washington, DC: Catholic University of America Press.

Hassing, R. F. (2017). Modern turns in mathematics and physics. In M. Rohlf (Ed.), The modern turn (Vol. 60, pp. 131-182). Washington, DC: Catholic University of America Press.

Hawking, S., \& Mlodinow, L. (2012). The grand design. New York: Bantam.

Hawley, J. F., \& Holcomb, K. A. (2005). Foundations of modern cosmology. Oxford: Oxford University Press.

Heil, J. (2017). Real modalities. In J. D. Jacobs (Ed.), Causal powers (pp. 90-104). Oxford: Oxford University Press.

Heller, M. (2011). Philosophy in science: An historical introduction. Dordrecht: Springer Science+Business Media.

Hellman, G., \& Shapiro, S. (2018). Varieties of continua: From regions to points and back. Oxford: Oxford University Press.

Jammer, M. (1993). Concepts of space: the history of theories of space in physics (3rd ed.). New York: Dover Publications.

Juarez, P. (2017). From the unity of the world to God: A teleo-cosmological argument for God's existence. Scientia et Fides, 5(2), 1-21.

Kastner, R. E., Kauffman, S., \& Epperson, M. (2018). Taking Heisenberg's potentia seriously. International Journal of Quantum Foundations, 4(2), 158-172.

Katzav, J. (2005). Ellis on the limitations of dispositionalism. Analysis, 65(1), 92-94.

Klein, J. (1992). Greek mathematical thought and the origin of algebra. Mineola, NY: Dover Publications.

Koons, R. C. (2014). Staunch vs. faint-hearted hylomorphism: Toward an Aristotelian account of composition. Res Philosophica, 91, 1-27.

Koons, R. C. (2018a). Forms as simple and individual grounds of things' natures. Metaphysics, $1(1), 1-11$.

Koons, R. C. (2018b). Hylomorphic escalation: An Aristotelian interpretation of quantum thermodynamics and chemistry. American Catholic Philosophical Quarterly, 92(1), 159178.

Kragh, H. (2009). Contemporary history of cosmology and the controversy over the multiverse. Annals of Science, 66(4), 529-551.

Lanao, X. and N. J. Teh. (2017). Dodging the Fundamentalist Threat. In W. M. R. Simpson, R. C. Koons, and N. J. Teh (Eds.), Neo-Aristotelian Perspectives on Contemporary Science (pp. 15-34). New York: Routledge.

Lange, M. (2008). Could the laws of nature change? Philosophy of Science, 75(1), 69-92.

Larenz, R. (2013). What can Thomistic philosophy of nature contribute to physics? Societal Studies, 5(2), 481-500.

Livanios, Vassilis. (2018). Hamilton's principle and dispositional essentialism: Friends or foes? 
Journal for General Philosophy of Science, 49(1), 59-71.

Leslie, J. (Ed.). (1999). Modern cosmology \& philosophy. Amherst, N.Y.: Prometheus Books.

Lewis, D. (1983). New work for a theory of universals. Australasian Journal of Philosophy, 61(4), 343-377.

Lewis, D. (1987). Philosophical papers volume II. Oxford: Oxford University Press.

Lewis, D. (1994). Humean supervenience debugged. Mind, 103(412), 473-490.

Lewis, D. K. (2001). Counterfactuals (reprint ed.). Malden, Mass.: Blackwell Publishing.

Maritain, J. (1940). Science and wisdom. London, New York: G. Bles, Scribner.

Maritain, J. (1951). Philosophy of nature. New York: Philosophical Library.

Maritain, J. (1995). Distinguish to unite, or, the degrees of knowledge. (G. B. Phelan, rrans., R. M. McInerny, Ed.) (The Collected Works of Jacques Maritain, vol. 7). Notre Dame, IN: University of Notre Dame Press.

Maritain, J. (1997). Towards a thomist idea of evolution. In R. M. McInerny, F. Crosson, \& B. Doering (Eds.), B. Doering (trans.), Untrammeled approaches (The Collected Works of Jacques Maritain, vol. 20, pp. 85-131). Notre Dame, IN: University of Notre Dame Press.

McCoy, C. D. (2018). On classical motion. Philosopher's Imprint, 18(9). http://hdl.handle.net/2027/spo.3521354.0018.009. Accessed 17 November 2018.

McMullin, E. (1969). Philosophies of nature. The New Scholasticism, 43(1), 29-74.

McMullin, E. (1981). Is philosophy relevant to cosmology? American Philosophical Quarterly, 18(3), 177-189.

Mullahy, B. (1946). Subalternation and mathematical physics. Laval théologique et philosophique, 2(2), 89-107.

Mumford, S. (2004). Laws in nature. London/New York: Routledge.

Needham, P. (2017). Macroscopic metaphysics: Middle-sized objects and longish processes. Cham: Springer International Publishing.

Novo Villaverde, F. J., Pereda, R., \& Sánchez Cañizares, J. (2018). Naturaleza creativa. Madrid: Rialp.

Oderberg, D. S. (2009). Real essentialism. London/New York: Routledge.

Oderberg, D. S. (2011). The world is not an asymmetric graph. Analysis, 71(1), 3-10.

Oderberg, D. S. (2013). No potency without actuality: The case of graph theory. In T. E. Tahko (Ed.), Contemporary Aristotelian metaphysics. Cambridge/New York: Cambridge University Press.

Peterson, J. (1996). Law and thomistic exemplarism. The Thomist: A Speculative Quarterly Review, 60(1), 81-108.

Plato. (1997). Plato: Complete works. (J. M. Cooper \& D. S. Hutchinson, Eds.). Indianapolis: Hackett Publishing Co.

Prigogine, I., \& Stengers, I. (1984). Order out of chaos: Man's new dialogue with nature. Toronto/New York: Bantam Books.

Pruss, A. R. (2013). Aristotelian forms and laws of nature. Analiza i Egzystencja, 24, 115-132.

Rovelli, C. (2018). Physics needs philosophy. Philosophy needs physics. Foundations of Physics, 48(5), 481-491.

Schaffer, J. (2009). Spacetime the one substance. Philosophical Studies, 145(1), 131-148.

Schaffer, J. (2013). The action of the whole. Aristotelian Society Supplementary Volume, 87(1), 67-87.

Sellars, W. (1963). Philosophy and the scientific image of man. In Empiricism and the 
philosophy of mind (pp. 1-40). London: Routledge \& Kegan Paul Ltd.

Simpson, W. M. R., Koons, R. C., \& Teh, N. J. (Eds.). (2017). Neo-Aristotelian perspectives on contemporary science. New York: Routledge.

Smart, B. T. H., \& Thébault, K. P. Y. (2015). Dispositions and the principle of least action revisited. Analysis, 75(3), 386-395.

Smith, W. (1999). From Schrödinger's cat to Thomistic ontology. The Thomist: A Speculative Quarterly Review, 63(1), 49-63.

Steinhardt, P. J. (2011). The inflation debate: Is the theory at the heart of modern cosmology deeply flawed? Scientific American, 304(4), 36-43.

Tegmark, M. (2003). Parallel universes. Scientific American, 288(5), 40-51.

Thomasson, A. L. (2007). Ordinary objects. Oxford: Oxford University Press.

Tolman, R. C. (1987). Relativity, thermodynamics, and cosmology. New York: Dover Publications.

Tooley, M. (1977). The nature of laws. Canadian Journal of Philosophy, 7(4), 667-698.

Unger, R. M., \& Smolin, L. (2014). The singular universe and the reality of time: A proposal in natural philosophy. Cambridge: Cambridge University Press.

Wallace, D. (2012). The emergent multiverse: quantum theory according to the Everett interpretation. Oxford: Oxford Univ. Press.

Wallace, W. A. (1979). From a realist point of view: Essays on the philosophy of science. Washington, DC: University Press of America.

Wallace, W. A. (1996). The modeling of nature: Philosophy of science and philosophy of nature in synthesis. Washington, DC: The Catholic University of America Press.

Weizsäcker, C. F. von. (2014). Carl Friedrich von Weizsäcker: Major texts in philosophy. (M. Drieschner, Ed.). Cham/Heidelberg: Springer.

White, Michael J. (1992). The Continuous and the Discrete: Ancient Physical Theories from a Contemporary Perspective. Oxford/New York: Oxford University Press, USA.

Whitrow, G. J. (1959). Structure and evolution of the universe: An introduction to cosmology (2nd ed.). New York: Harper \& Row. 